\title{
Dignidad humana y diálogo intercultural. Posibilidades y condiciones del diálogo entre religiones y convicciones (Weltanschauungen)
}

\author{
Alfred Fernández \\ Copresidente, Collège Universitaire Henry Dunant \\ Director General, OIDEL (derecho a la educación y libertad \\ de enseñanza) Ginebra
}

SUMARIO: 1. Elementos y tipos De Weltanschaungen.- 2. Riesgo y NECESIDAD DEL DIÁLOGO.- 3. LAS POSICIONES ANTE EL DIÁLOGO.- 4. UNA EXPERIENCIA HISTÓRICA: LA ÉPOCA MEDIEVAL.5. LAS CONDICIONES DEL DiÁLOGO ENTRE WELTANSCHAUNGEN.6. BiBLIOGRAFÍA.

La necesidad del diálogo intercultural es un tópico. Quizás uno de los más presentes en la cultura actual. Tanto se ha escrito sobre el tema que extraña que no se haya avanzado más en él. Incluso a veces parece que se ha regresado y ello a pesar de iniciativas de envergadura como las normas internacionales sobre la diversidad, el ecumenismo entre confesiones cristianas, o las numerosas conferencias organizadas desde el fin de la segunda guerra mundial. No deja de causar perplejidad el poco avance. Es verdad que buscar un terreno común no parece fácil. En nuestra opinión, el mayor logro en este terreno ha sido la adopción de la Declaración Universal de Derechos Humanos y, en general, del corpus de instrumentos internacionales redactados desde 1948.

En este texto, que se nutre del trabajo de varios años sobre todo en el ámbito internacional ${ }^{1}$, vamos a presentar

1 Sobre este tema hemos escrito Los presupuestos del diálogo intercultural (2002), OIDEL, Working Papers 5, Ginebra y Diversidad cultural y universali- 
algunas reflexiones sobre el diálogo entre Weltanschauungen - concepciones del mundo- que nos parecen ser el núcleo duro (core content) del dialogo intercultural. Hemos preferido esta denominación, Weltanschauungen (W), concepción o visión del mundo, a la de religión y convicción porque estimamos el concepto más apropiado por ser englobante. Religión y convicción son les términos utilizados en los instrumentos internacionales, por ejemplo en la $D e-$ claración sobre la eliminación de todas las formas de intolerancia y de discriminación fundadas en la religión o las convicciones (1981). Sin embargo, esta asimilación, siendo cómoda, plantea problemas como ha mostrado G. Marcel ${ }^{2}$.

Según una tipología generalizada, se puede concebir el diálogo intercultural al menos a tres niveles:

1. Vital, experiencia de la realidad del otro en las relaciones de la vida corriente o en la colaboración en proyectos comunes, sobre todo prácticos.

2. Debate e intercambios entre expertos representantes de las diferentes culturas con una dimensión fundamentalmente cognitiva.

3. Específico a las religiones, intercambio entre experiencias religiosas y entre praxis cultuales ${ }^{3}$.

Abordar la temática del diálogo Intercultural en general, por tanto, es tarea difícil tales son los niveles posibles de este diálogo. Por ello en este estudio, repetimos, hemos reducido el campo a las creencias y convicciones, partiendo de la idea que creencias y convicciones representan los núcleos duros de las culturas, y que casi siempre implican cuestiones "no negociables". Por ello parecen constituir el

dad de los derechos humanos. Materiales sobre los presupuestos del diálogo intercultural (2004), Anuario de Derechos humanos, Instituto de Derechos Humanos, Universidad Complutense, Madrid, volumen 5, pp. 243-254. Desde 2002 dirigimos un Seminario permanente sobre el diálogo intercultural que ha producido en particular un documento de síntesis Dialogo intercultural y sociedad de la información. Se puede encontrar el texto en www.oidel.ch.

2 cfr G. MarCel (1967) Foi et realité, Aubier Montaigne, París, pp. 85 y ss.

${ }_{3}$ Nos hemos inspirado para esta tipología del documento del Consejo Pontificio para el Diálogo Interreligioso de la Iglesia Católica Romana, Diálogo y anuncio (1991), Roma, sobre todo del párrafo 42. 
obstáculo máximo al diálogo que debe naturalmente —o al menos así se entiende - conducir a una negociación o arbitraje, sobre la base de una argumentación racional. Volveremos sobre este tema.

\section{Elementos y tipos De Weltanschaungen}

Reducción epistemológica entonces a las Weltanschaungen, concepciones del mundo. Veremos con más detalle los diferentes tipos de W, pero de momento es suficiente con caracterizarlas como religiones o convicciones. Las W constituyen en nuestra opinión el núcleo duro de las culturas porque la cultura hace referencia al sentido (de la vida).

Recordemos que esta cuestión es esencial para el ser humano. Sin respuestas, el hombre se sumerge en el "vacío existencial" porque el ser humano es un ser de sentido dice V. Frankl ${ }^{4}$. El sentido de la vida se encuentra no se crea, prosigue Frankl, y la facultad del sentido es la conciencia moral en la que surgen los valores morales como categorías universales de sentido, típicas y recurrentes que caracterizan la condición humana ${ }^{5}$.

La religión y la convicción son fuente de este sentido, aportan respuestas al hombre que quiere saber que va a ser de él. Quiere saber si está "condenado a ser libre" (Sartre), si es un "ser para la muerte" (Heidegger), si es "imagen de Dios" (Génesis) ou un "ser de don" (Bruaire). El sentido depende, en gran parte, de la Weltanschauung que se adopte.

Tres elementos se encuentran en toda W: una visión del mundo, del yo y de la causa del mundo y del yo, que

4 V. Frankl (1987) El hombre doliente, Herder, Barcelona, pp. 11 y ss.

${ }^{5}$ Según Frankl, el sentido de se encuentra de tres maneras. Primeramente a través de una obra o buena acción. En segundo lugar haciendo la experiencia de algo o de alguien. Puede ser la experiencia de la bondad, de la verdad o de la belleza, por ejemplo entrando en contacto con la naturaleza o, mejor aún, conociendo la unicidad de un ser humano a través del amor. Por último existe una tercera manera de encontrar el sentido. Reside en la actitud que se toma ante un sufrimiento inevitable. Estando en una situación desesperada, el ser humano puede escoger la actitud que quiere: morir con dignidad, asumir sus sufrimientos. 
podría ser entendido como el principio en la filosofía griega: el arjé.

"Cuando el hombre se ha colocado fuera de la naturaleza y ha hecho de ella su «objeto» - y ello pertenece a la esencia del hombre y es el acto mismo de la humanificación- se vuelve en torno suyo estremeciéndose, por decirlo así y pregunta: ¿Dónde estoy yo mismo?, ¿Cuál es mi puesto? ... En esta vuelta en torno suyo, el hombre hunde su vista en la nada por decirlo así. Descubre esta mirada la posibilidad de la «nada absoluta» y esto le impulsa a seguir preguntando: ¿Porqué hay un mundo?, ¿porqué y como existo "yo»? Repárese en la rigurosa necesidad esencial de esta conexión que existen entre la conciencia del mundo, la conciencia de sí mismo y la conciencia formal de Dios en el hombre... La conciencia del mundo, la conciencia de sí mismo y la conciencia de Dios forman una indestructible unidad estructural" (Max Scheler, 1960, pp. 109-110).

Todas las $\mathrm{W}$ presentan una articulación de estos tres elementos, aunque esta articulación se manifiesta de formas muy diversas. Puede darse una unificación de las tres, - es el caso del panteísmo o del marxismo- o bien la supresión de uno de los elementos como el mundo en el caso del idealismo o de Dios/principio en la filosofía de Sartre. El yo puede aparecer igualmente como el todo y lo mismo puede ocurrir con el mundo o Dios. En realidad todas las combinaciones son posibles y todas, de hecho, se han dado en la historia del pensamiento. Es evidente que las $\mathrm{W}$ de tipo religioso hacen hincapié en el principio/Dios que existe de modo independiente y que juega el papel esencial. Las W de tipo convicción pueden implicar la existencia de Dios o no, y ha nacido esencialmente en el terreno cultural occidental desde la Ilustración.

Dicho esto, nos parece que las $\mathrm{W}$ pueden ser de cuatro tipos según su origen ${ }^{6}$ :

${ }^{6}$ Para establecer esta tipología nos hemos inspirado en el libro de G. MARCEL citado en nota 2. 
1. Las primeras podrían ser las filosofías, construcciones racionales por lo general, que pueden ser puramente individuales y que corresponden a lo que se denomina convicciones. La característica esencial de las convicciones es que son individuales, su fundamentación es personal y tienen una gran capacidad de cambio ya que dependen de la decisión individual. Basadas en ideas filosóficas existen también convicciones que se configuran como escuelas de pensamiento. Tienen menos capacidad de cambio y suelen servir simplemente de apoyo a las convicciones individuales. No suelen formar una verdadera comunidad identificable como tal. Están próximas a las ideologías pero no deben confundirse con ellas.

2. Las ideologías son W más estructuradas colectivamente y esto les diferencia de las filosofías. Las ideologías crean comunidades que pueden ser férreas y que tienden a absolutizar ciertos principios racionales. Pueden citarse como ejemplo el marxismo, el feminismo radical o la ecología en su versión extrema. La ideología suele crear un grupo próximo en sus adhesiones al que suscitan las religiones. Se podría pensar - y se ha dicho con frecuencia desde Max Weber- que las ideologías son una evolución secularizada de las religiones.

3. En tercer lugar las W pueden venir de una "revelación", de un mensaje que la divinidad ha transmitido a una persona o a un grupo. La mayoría de las $\mathrm{W}$ pertenecen a este tipo. La gran mayoría de la población mundial conforma su vida guiándose por una $\mathrm{W}$ de este tipo. El contenido del mensaje suele ser un "depósito"7. Este carácter de depósito implica que la "revelación" no depende de los miembros de la comunidad, preexiste a ella y los miembros no están habilitados para cambiarlo. Dado que es un mensaje

${ }^{7}$ Esta noción de depósito es fundamental por ejemplo en el cristianismo. Ver sobre este tema a modo de ilustración K. KocH (2000) Le Credo des chrétiens. Une lecture contemporaine, Saint Augustin, Saint Maurice, pp. 15 y ss. 
transmitido por la divinidad tiene un valor superior a la razón humana. No entramos aquí en el debate si existe continuidad entre la razón humana y la razón divina ${ }^{8}$.

4. Próximas a las W que emanan de "revelaciones" se encuentras las tradiciones y/o los mitos fundadores igualmente entregados por el pasado. Se diferencian de las revelaciones en que no son necesariamente de origen divino. Incluso a veces su origen no importa tanto como el hecho de que representan la sabiduría de una comunidad. Este aspecto de legado es esencial, mientras que para las revelaciones el legado es aspecto puramente circunstancial: es legado hoy, un día no lo fue y el mensaje sigue siendo el mismo. Las tradiciones y los mitos que han sido desvalorizados por la modernidad han sido rehabilitados como modos "alternativos" de descripción de la realidad. Son menos permeables a la razón que las revelaciones, porque su valor reside precisamente en este carácter alternativo de interpretación de lo real.

Es evidente que no todas las $\mathrm{W}$ tienen el mismo peso específico a nivel sociológico ni de conformación de las mentalidades. Las religiones representan más del $80 \%$ del total de $\mathrm{W}^{9}$. Por ello parece razonable dedicarles un tratamiento diferenciado. M. Eliade ha llegando a afirmar que:

"lo sagrado es un elemento en la estructura de la conciencia y no un estadio en la historia de la conciencia... En otros términos ser —o más bien devenir hombresignifica «ser religioso». Porque lo sagrado es lo real por excelencia". (M. Eliade, 1982, pp. 7-8.).

${ }^{8}$ Este es el tema central des discurso de Benedicto XVI en Ratisbona. Sobre este tema pueden leerse los trabajos de de MuRALT en particular (2002) La estructura de la filosofía política moderna. Sur orígenes medievales en Escoto, Occam y Suárez, Itsmo, Madrid.

9 Según un estudio de la Encyclopædia Britannica los no religiosos son $14.7 \%$ de la población mundial y los ateos $3.8 \%$. Información tomada de fr.wikipedia.org/wiki/Ath\%C3\%A9isme_\%C3\%A9tudes_et_statistiques 
Eliade va incluso más lejos, el hombre es por naturaleza un homo religiosus. El historiador A. Toynbee ${ }^{10}$ subraya, por su parte, que no ha existido hasta nuestros días ninguna gran civilización que no haya sido religiosa. La única excepción es la sociedad occidental. ¿Estamos ante una mutación esencial? Lo parece viendo la hegemonía de la cultura occidental a escala mundial. Pero desde los años ochenta los pensadores constatan que el fenómeno de la secularización no es irreversible. Después de la Ilustración, la religión continúa existiendo en cuanto modo de hacer frente a la contingencia, como constata de H. Lubbe que muestra la resiliencia de la religión en el siglo XXI ${ }^{11}$.

Pero independientemente de su origen, todas las $\mathrm{W}$ son creencias en el sentido de:

"mecanismo, postura —o impostura- del espíritu, como manera de estar ante el mundo" ... Desde un punto de vista filosófico se puede retener la expresión forjada por Paul Ricoeur cuando evoca el "enigma de tener-por-verdadero" (tenir-pour-vrai). La creencia, añade "designa una actitud mental de aceptación o de asentimiento, un sentimiento de persuasión, de convicción íntima" (J. C. Guillebaud, 2005, p. 25).

Las creencias -incluso las racionales de tipo filosófico- no suelen adoptarse mediante un análisis racional estricto. Suelen ser otros factores los que intervienen en la aceptación de algo como verdadero. Pero por las razones que sean todos adoptamos una creencia para "estar en el mundo", para poder comprender y dar sentido al mundo (Cf. supra). Por ello, el diálogo que puede poner el entredicho esta creencia, que es posición frente al mundo al mismo tiempo, presenta dificultades. No podemos, es evidente, cambiar cada día de creencia, de posición frente al mundo.

El dialogo supone pues un riesgo. Pero, al mismo tiempo, es una necesidad. Necesidad ontológica porque el hom-

10 cfr A. ToynBee (1952), Estudio de la Historia, Compedio, Emecé, Buenos Aires. Sobre todo los capítulos VI y VII (volumen 2).

11 H. LubBe (1986), Religion nach der Aufklärung, Graz. 
bre es un ser que se construye en la relación dialógica con los otros: no hay yo sin tú como diría Buber ${ }^{12}$. La persona es un dedans qui a besoin du dehors, un interior que necesita de lo exterior (E. Mounier). Riesgo también, porque esta apertura hacia el exterior puede poner en entredicho la identidad. Por ello, el diálogo entre W aparece como particularmente difícil, y por ello, a menudo, se estima que es simplemente imposible porque instalados en la aceptación de algo, no tenemos porqué "dejar de tener por verdadero lo que tenemos por verdadero".

En el ámbito internacional el diálogo entre W aparece, en un mundo cada vez más complejo, interdependiente e ilegible, como una exigencia del "vivir juntos" de modo pacífico. Cuando el diálogo no existe en una sociedad pluralista, fácilmente, las relaciones pueden tornarse violentas. Se podría encontrar otra finalidad al diálogo entre $\mathrm{W}$ —más importante de vista teórico pero con menos implicaciones prácticas-, nos referimos a la búsqueda común de la verdad. Habría así dos finalidades: una política en el sentido general del término y otra de tipo cognitivo. Todo el mundo está convencidos de que la paz social depende de la capacidad de diálogo entre ideologías, creencias o religiones diversas. El diálogo se contempla como un instrumento de preservación de la convivencia o al menos de la coexistencia, convencidos como estamos de que la ignorancia suele engendrar separación y, a la postre, violencia.

Pero estas afirmaciones, excesivamente generales, necesitan matizarse e incluso verificarse empíricamente. El conocimiento del otro no es suficiente para impedir los comportamientos violentos. Es condición necesaria, pero no suficiente; se necesita, además, la voluntad y la capacidad de "vivir juntos". El dialogo dia-logos se entiende entonces como una palabra compartida, que implica una argumentación posible. La posibilidad de esta argumentación se funda en una comunidad de conceptos sino de realidades, sin los cuales la argumentación carece de base. Esta palabra compartida tiene una finalidad práctica:

${ }^{12}$ M. Buber (1959), La vie en dialogue, Aubier Montaigne, París. 
debe facilitar este "vivir juntos" por medio de la obra común: la co-operación, que esto significa esta palabra, la capacidad de construir juntos una sociedad en una operación común.

En el momento presente, el diálogo se muestra fudamentalmente como una necesidad de tipo político y a la poste pragmático-instrumental. Y esta necesidad aparece en un doble debate presente de manera particular en la sociedad occidental, sociedad que sólo recientemente ha asumido de modo pleno la existencia de la diversidad como valor ${ }^{13}$. Este reconocimiento de la diversidad es ciertamente global, de ámbito mundial, pero se manifiesta de modo especialmente significativo en la cultura occidental. En Occidente la organización política —el Estado-nación- rechazaba la existencia "legal" del pluralismo que se contemplaba, hasta fecha reciente, como un obstáculo a la cohesión social.

En la sociedad occidental nos parece urgente instaurar dos diálogos en el terreno de las W. El primero es el diálogo entre la religión cristiana y la no-creencia, también caracterizada como secularismo. El segundo es el diálogo entre sociedad occidental y/o cristianismo e Islam. Puede que incluso nos encontremos ante dos tipos diferentes de diálogo con el Islam: uno en el ámbito religioso y otro en el ámbito de la organización social.

En estos diálogos, pero sobre todo en el diálogo con el Islam, estamos en presencia de dos $\mathrm{W}$ con pretensiones universales. Es necesario ponerlo de relieve porque, para algunos, esta pretensión de universalidad significa el principal obstáculo al diálogo. Religiones universales o ideologías universales no pueden coexistir en el espacio público, precisamente por ese carácter universalizante. Es cierto que se han hecho siempre acomodaciones de esta pretensión, acomodaciones que van del gheto a la protección de las minorías, pero, cuando dos $\mathrm{W}$ universalizantes

${ }_{13}$ Sobre todo desde la adopción por la UNESCO de la Declaración Universal sobre la Diversidad Cultural en 2001 
se han encontrado en la historia, casi siempre, la relación ha sido conflictiva.

Pero es necesario afirmar igualmente que, este carácter universalizante, vuelve a las $\mathrm{W}$ de estas características más aptas para trascender culturas determinadas y crear puentes entre mundos diferentes. Es una reducción peligrosa y falsa, por ello, identificar el cristianismo con la cultura occidental. El cristianismo, pero también el marxismo o el positivismo, se han enculturado en todos los continentes. El conflicto suele acontecer cuando dos W universalizantes se disputan un territorio o una cultura, un espacio cultural y/o político.

\section{RIESGO Y NECESIDAD DEL DIÁLOGO}

Hemos dicho que el diálogo en $\mathrm{W}$ conlleva el riesgo de perder la propia identidad. Y al mismo tiempo, hemos afirmado, existe una necesidad ontológica del diálogo. Rof Carballo lo ha mostrado en "Violencia y ternura", título significativo.

"El hombre - dice Rof Carballo- tiene desde el comienzo de la vida tres necesidades fundamentales: la de encontrar respaldo en un grupo de preferencia el familiar; segundo la de estar supeditado a alguien con autori$d a d$ que le oriente en el manejo de la realidad externa. En tercer lugar la necesidad no menos imperiosa que las otras dos de ser protagonista, de distinguirse de los demás, de desarrollar de manera independiente, autónoma, su pequeña persona" (Rof Carballo, 1997, p. 42).

El ser humano necesita obedecer y ser protegido y amparado, necesita seguridad y al mismo tiempo necesita independencia, autonomía. Amparo, protección y autonomía van de par. Necesita el ser humano orden, autoridad, que le otorgue seguridad y le proporcione, con este orden, la posibilidad de comprender el mundo, que aparece, al comienzo, como algo caótico y hostil. La urdimbre constitutiva de la personalidad es a la vez amparadora y liberadora, ordenadora, permite la apertura al mundo a través de la 
madre, otorga confianza básica y presenta al mundo como algo fiable y seguro. Tiene una función de horizonte y de integración, señala lo bueno y lo malo, lo prohibido y lo permitido.

Esta particular manera de ser de lo humano se origina en el hecho de que el hombre no nace acabado: "está necesitado de completarse. Lo que le completa injertándose sobre él y acabando de constituirle es el grupo social". Aquello que le completa es: "primero a lo que siendo invalidísimo infante, urdimbre sin cerrar le ha completado con la trama del grupo que le acoge, es decir la madre y la familia. Pero después, más tarde, con aquello que el inconscientemente ha buscado que le complete, el grupo en el que se inscribe o inserta" (Rof Carballo, 1997, p. 99).

Esta manera de ser que interrelaciona, biología y cultura es particular al ser humano. "La herencia genética, (...) no hace más que presentar al ser vivo unas posibilidades de juego como un croupier (...) Es importante como está «construida» la baraja y como se juega con ella. Pero lo primordial son las convenciones, o reglas, o programa con arreglo al cual ha de jugarse. Esas reglas o programa previo de toda vida no son exclusivamente hereditarios, sino que se preparan en los primeros meses y años de la existencia por una relación transaccional (dos sistemas de causas que están influyéndose de manera recíproca) con los seres que tutelan la vida infantil. Es una especie de trama sobre la que se teje toda la vida humana. (...) Es a esa trama primera a la que he llamado urdimbre constitutiva" (Rof Carballo, 1997, pp. 103-104).

Esta urdimbre o trama constitutiva es pues psico-biológica, hace entrar en relación lo psíquico y lo biológico. Esta relación es además transaccional: causas que se modifican mutuamente, y programadora: ordena las piezas biológicas según las reglas que el grupo aporta.

Rof Carballo enumera dos otras urdimbres que constituyen la persona: la urdimbre de orden que nos permite adoptar las normas sociales y que procede a una radical ordenación del mundo y la urdimbre de identidad. La urdimbre de identidad que se constituye en la adolescencia: 
"el individuo confrontando la imagen que de sí mismo se forma con la que de él se hacen los demás adquiere una idea de «sí mismo», esto es conciencia de su mismidad, de su ser persona única" (Rof Carballo, 1997, p. 108).

El análisis de Rof pone de manifiesto dos cosas esenciales. Primero que la persona no se constituye sin el grupo, y que esta acción del grupo es tan importante que incluso modifica la biología. Segundo, que esta necesidad de completitud conlleva un riesgo fundamental, deja desvalido al ser humano frente al grupo y a los otros en general: le hace dependiente, sobre todo de la familia y la madre, pero en general del grupo social. Necesita el hombre relacionarse con el grupo pero esta relación puede privarle de identidad.

\section{LAS POSICIONES ANTE EL DIÁLOGO}

Así dialogar sobre la $\mathrm{W}$ puede ser percibido como negociar sobre la identidad y esto es verdaderamente difícil. Por ello nos parece importante examinar las positiones que se pueden adoptar en el marco del diálogo entre W. Desde nuestro punto de vista, existen al menos cuatro posiciones/acercamientos al diálogo entre $\mathrm{W}$ :

1. La que estima que todas las $\mathrm{W}$ tienen razón y que el objetivo del diálogo es llegar a ese reconocimiento de igual validez: es la opción que la mentalidad actual más difundida considera adecuada. Se basa en un relativismo de principio. Es la posición, por ejemplo, de la teología pluralista de Hick ${ }^{14}$.

2. La que intenta llegar a un acuerdo entre las W, sea mediante una $\mathrm{W}$ comprensiva, o mediante un acuerdo racional que supere las $\mathrm{W}$ particulares. Es lo que intentó Rousseau con su religión civil o los sincretismos de corte oriental.

14 J. Hick (2004) An Interpretation of Religion, London, Macmillan and New Haven, Yale University Press. 
3. La que supone que sólo una $\mathrm{W}$ es verdadera y que ésta es la propia. Esta posición puede ser exclusivista o inclusivista. Para la exclusivista, las otras W son erróneas según el principio de que la verdad es una y en consecuencia sólo puede encontrarse en un lugar. La variante llamada inclusivista entiende que la $\mathrm{W}$ propia puede ser compartida por varias $\mathrm{W}$ aunque en grados diversos, siendo la propia, sin embargo, la genuina representante de la verdad. Esta es la posición tanto de las grandes religiones como de la ciencia experimental.

4. Podría aún presentarse otra manera de ver que consiste en pensar que la búsqueda de una verdad es inútil y que, en consecuencia, el dialogo sólo puede constatar la imposibilidad de decidir. Es la postura del escepticismo.

Todas las posiciones presentan posibilidades pero también límites, valga como muestra la dificultad para encontrar un modo verdaderamente operacional, práctico, para el diálogo en las sociedades actuales. En una primera aproximación, la opción que postula un reconocimiento de igual validez de las $\mathrm{W}$ es la que parece ofrecer más posibilidades y la más aceptada por la mentalidad actual. Esta mentalidad se nutre del pluralismo ideológico presente en casi todos los países y de la experiencia de la intolerancia que suelen suscitar las W universalizantes.

Sin embargo, esta posición, de corte relativista, plantea graves inconvenientes. Citemos solamente cuatro:

1. Parece difícil concebir desde el punto de vista epistemológico que esta posición, que elimina de facto la posibilidad de una verdad absoluta, pueda ser la única aceptable. Pero afirmar que las verdades son cambiantes sólo puede significar dos cosas: "o bien que lo que llamamos verdades no son más que proyección subjetiva variable, arbitraria o convencional, lo que lleva al puro escepticismo; o bien conservamos a la palabra verdad un sentido fuerte de relación a lo que existe y en esta caso hay que atribuir al espíritu 
humano un verdadero poder de creación. Es decir hacer de él un Absoluto" (H. Hude, 1991, pp. 19-20).

2. Esta posición significa renunciar a la búsqueda de la verdad. Esta búsqueda, sin embargo, es el fundamento explícito o implícito de la investigación científica y filosófica. "Todo espíritu, por el simple hecho de que es racional apunta y pretende a la universalidad y no puede no pretender y no apuntar a ella. Y es imposible juzgar que se piensa la verdad sin juzgar que piensa la falsedad el que sostiene lo contradictorio. No hay aquí intolerancia: es la simple ley de la razón a la que nadie puede sustraerse" (H. Hude, 1991, pp. 91-92).

3. Es impracticable, porque desde el momento en que todos los interlocutores aceptasen esta posición -a cada uno su verdad- el diálogo se acaba, los participantes no pueden más que constatar sus diferencias. Esta constatación no permite la construcción de un proyecto común. No permite siquiera diálogo, porque no hay nada que buscar. En realidad esta postura es la máxima expresión de la negación del diálogo, o mejor, es una postura que impone una "verdad" bajo capa de no hacer ninguna imposición.

4. Desde el punto de vista práctico es impensable que todas la $\mathrm{W}$ renuncien a su pretensión de verdad en un momento dado:. ¿que autoridad podría obligarles sin caer en la intolerancia o la arbitrariedad, ¿que poder, y que tipo de poder, podría decretarlo?, y ¿que resultado tendría una imposición de este tipo?

Parece sumamente difícil, sobre todo, conciliar esta posición con el respeto de la dignidad humana ya que, como se vé, esta posición desemboca en el nihilismo e incluso en el absurdo. La W —como hemos dicho— responde a la cuestión del sentido de la vida. Responde a las preguntas esenciales del hombre, las que le comprometen enteramente, y que Kant enumera en su Lógica: ¿que puedo saber?, ¿que debo hacer? ¿que puedo esperar? y ¿que es el hombre? Estos interrogantes son legítimos y forman parte 
esencial de la dignidad humana (J. Hersch). No podemos ni despreciarlos ni minusvalorarlos.

\section{UNA EXPERIENCIA HISTÓRICA: LA ÉPOCA MEDIEVAL}

La experiencia histórica es de utilidad para saber si un diálogo entre $\mathrm{W}$ es posible. Así, conviene preguntarse si ha existido en la historia algún momento, una situación, de "encuentro entre civilizaciones" como diría Toynbee, en la que varias $\mathrm{W}$ han "vivido juntas" dialogando. Y, si se ha dado, examinar las condiciones en la que la se dio, para explorar la posibilidad de "repetir" la experiencia.

Existe, al menos un ejemplo histórico en la Europa occidental que podemos estudiar en este sentido. Se trata del diálogo filosófico-teológico entre cristianismo, judaísmo e Islam en la Edad Media. Este diálogo se manifiesta, por ejemplo, en la utilización que hace Tomás de Aquino de las ideas de Averroes y Maimónides ${ }^{15}$. Ambos autores son citados abundantemente en la obra del teólogo cristiano, sin que ello le impida criticar las W islámica y judía. Existió en ese momento histórico lo que R. Arnaldez ha llamado comunidad de pensamiento ${ }^{16}$. ¿Cómo ha sido posible este diálogo entre $\mathrm{W}$ aparentemente incompatibles?

15 Sobre las relaciones entre Tomás de Aquino y Maimónides ver el excelente y voluminoso trabajo de A. WoHLman (1988), Thomas d'Aquin et Maïmonide, un dialogue exemplaire, Cerf, Paris. Sobre las relaciones entre Tomás de Aquino y Averroes ver el clásico de M. Asín PALACios (1904) El averroísmo teológico de Santo Tomas de Aquino, Zaragoza. Sobre la filosofía islámica y judía en la Edad Media sigue siendo imprescindible el libro de S. Munk (1988), Mélanges de philosophie juive et arabe, Vrin Paris. Una buena presentación de la filosofía islámica se encuentra en el clásico H. CoRBIN (1964), Histoire de la philosophie islamique, Gallimard, col Idées, Paris.

16 R. ARnaldez (1993), A la croisée des trois monothéismes. Une communauté de pensée au Moyen Age, Paris, Albin Michel. Gilson estima que se sabe aún poco de la influencia de la filosofía islámica y judía sobre la filosofía cristiana. "Estoy persuadido que esta deuda es considerable pero no se conocerá la extensión ni la naturaleza mientras no se intente al menos un ensayo provisional del tipo del que yo he hecho para la filosofía cristiana" E. GiLson, (1969) L'esprit de la philosophie médievale, Vrin, París, p. 378, nota 1. 
"La confrontación entre Maimónides y Tomás —dice I. Leibowitz- es posible porque creen uno y otro en la fuente divina y única de su fé: las Escrituras que lee el primero a la luz de la ley y el segundo del Evangelio. Tienen igualmente en común la concepción aristotélica del mundo y los conceptos de esta filosofía en materia de lógica, de epistemología y de ontología". (A. Wohlman, 1988, prólogo. p. 10). Dicho de otro modo, si analizamos esta comunidad de pensamiento vemos que se basa en dos presupuestos fundamentales.

El primero es la base racional común nacida de la filosofía griega esencialmente de Platón y Aristóteles que permite la utilización de los mismos conceptos filosóficos: sustancia, potencia, esencia, o ser. La concepción central de la metafísica tomista, el esse, y la distinción entre esencia y existencia se construye en diálogo con Avicena y Averroes ${ }^{17}$.

La segunda es que los tres elementos que se encuentran en toda W (supra): el mundo, el yo, y el principio (la causa del mundo y del yo), se articulan del mismo modo en las tres W: el mundo, el principio/Dios, y el yo son tres realidades distintas. El mundo y el yo han sido creados por Dios y el hombre tiene la capacidad de conocer el mundo directamente y a Dios indirectamente. Como dice Arnaldez: "los encuentros de los tres monoteísmos fueron fructuosos bajo la mirada de Dios, cuando fueron inspiradas por una cierta comunidad de aspiraciones, espirituales e intelectuales, por concepciones concordantes sobre Dios, sobre el mundo sobre el hombre, sobre las relaciones del hombre con el mundo y Dios, en relación con los inevitables problemas que plantea el conocimiento de la verdad y del bien, del origen del hombre, de su finalidad aquí en la sociedad y en el más allá en una palabra del valor y del sentido de la vida" (R. Arnaldez, 1993, pp. 7-8). He aquí resumida de manera sintética la comunidad de pensamiento sobre la que reposan judaísmo, cristianismo e Islam. Existe entre ellas un elemento común igualmente de

17 Cfr. E. GiLson (1972), Le thomisme. Introduction a la philosophie de Saint Thomas d'Aquin, Vrin, Paris, pp. 189 y ss. 
otro orden: las tres son W basadas en "revelaciones" que dicen emanar de un tronco común.

Si intentamos ahora ir más allá y ver las condiciones que se hallaban reunidas en ese momento histórico para permitir el diálogo podríamos enunciar cuatro:

1. Igualdad entre las diferentes W, aunque esta igualdad era relativa, ya que el cristianismo se encontraba en posición dominante en Occidente.

2. Reciprocidad entre W: cada una tiene algo que aportar y algo que recibir de la otra. Para que esta reciprocidad se dé es necesario antes un reconocimiento de la validez de la aportación del otro.

3. Existencia de "algo común" (conceptos, realidades) elementos transculturales presentes en las W, en particular en los elementos constitutivos de toda W.

4. Existencia de una finalidad común: algo que motiva la necesidad de entrar en diálogo. Es el caso de la época medieval fue la búsqueda de la verdad la que motivó el diálogo, lo que no impidió fuertes tensiones.

Vamos a detenernos un momento en esta última condición porque encierra una paradoja. Muestra que no sólo la afirmación de verdades absolutas no obstaculiza el diálogo sino que puede al contrario ser un acicate para el debate que llevará a las $\mathrm{W}$ incluso de disputas públicas, como la de Barcelona ${ }^{18}$ o a una abundante literatura en torna a la cuestión de la vera religio como en Nicolás de Cusa $^{19}$ y R. Llul ${ }^{20}$.

Pero hay algo más paradójico aún para la mentalidad actual, esta comunidad de pensamiento medieval se estableció entre $\mathrm{W}$ que vienen de revelaciones de tipo religioso

18 Ver la version judía en NAHMANIDE (1984), La dispute de Barcelone, Paris, Verdier. Se trata de una version moderna con una introducción a la problemática y documentos anexos de la versión de WAGENSEIL, Tela ignea Satanae, editada con intención polémica en Suiza (Altdorf, 1681).

${ }^{19}$ Una buena presentación de las ideas del Cusano y del texto de $L a$ paz de la fe se encuentra en NICOLAS DE CUES (1942), Euvres choisies, con una introducción de M. DE Gandillac, Aubier Montaigne, Paris.

${ }^{20}$ R. Llul (1901), Libre del gentil i los tres sabis, Palma de Mallorca, Hijas de Colomar. 
y, en consecuencia, "no negociables" por principio. Las circunstancias tampoco eran propicias porque, como hemos apuntado, a menudo los intercambios se produjeron en periodo de tensiones políticas e incluso de guerras. Todas las condiciones estaban reunidas para que este diálogo no se diese y, sin embargo, se produjo y de modo ejemplar.

Cabría también preguntarse sobre que versó el diálogo en este periodo histórico. Los temas esenciales giraron en torno a la cuestión de la vera religio, de la teología fundamental, de la crítica de las fuentes de la revelación y de la crítica textual tal como aparecía en esos momentos y que era más bien modesta. Estos debates se llevaron incluso a la plaza pública constituyéndose así un debate sino ciudadano sí en presencia de los ciudadanos, con una apertura que no volvió a producirse salvo en el periodo de la Reforma pero sólo entre grupos cristianos.

\section{LAS CONDICIONES DEL DIÁLOGO ENTRE WELTANSCHAUNGEN}

La experiencia medieval manifiesta, en primer lugar, que ha existido diálogo al nivel de $\mathrm{W}$, segundo, que no existe una imposibilidad a priori y tercero, que este diálogo implica ciertas condiciones. Pero, además, el ejemplo muestra, contra una opinión corriente, injustificada pero tenaz, que la afirmación de verdades absolutas no obstaculiza el diálogo.

A este respecto, la Declaración de principios sobre la tolerancia adoptada por la UNESCO en 1995 aporta elementos interesantes. En su artículo 1.2 se dice:

"Tolerancia no es lo mismo que concesión, condescendencia o indulgencia. Ante todo, la tolerancia es una actitud activa de reconocimiento de los derechos humanos universales y las libertades fundamentales de los demás".

Y en el artículo 1.4: 
"practicar la tolerancia no significa tolerar la injusticia social ni renunciar a las convicciones personales o atemperarlas. Significa que toda persona es libre de adherirse a sus propias convicciones y acepta que los demás se adhieran a las suyas. Significa aceptar el hecho de que los seres humanos, naturalmente caracterizados por la diversidad de su aspecto, su situación, su forma de expresarse, su comportamiento y sus valores, tienen derecho a vivir en paz y a ser como son. También significa que uno no ha de imponer sus opiniones a los demás".

"Es porque su compromiso hacia lo que el cree verdadero puede ser absoluto - dice J. Hersch-que hay violación de lo humano al intentar imponerle por fuerza una convicción diferente de la suya (...) El absoluto de la convicción o de la exigencia moral de la que deriva su conducta exige del otro ser humano, no una mayor tibieza de convicción o de exigencia moral, sino más bien un absoluto respeto de esta convicción o de esta exigencia diferente incluso si uno se encuentra muy lejos de compartirla. Este es el fundamento de los derechos humanos. Y es también el fundamento de la verdadera tolerancia, que no sacrifica nada de la verdad" (J. Hersch, 1995, p. 49).

Retendremos de estas afirmaciones tres ideas. La primera es que la tolerancia y, por ende, la relación al otro, no es abstención, implica acercamiento, por tanto interés por el otro, diálogo. La segunda es que esta relación debe respetar los derechos fundamentales, la dignidad humana y la pretensión de verdad de otro: el derecho del otro a ser como es. Se rechaza, en consecuencia, la violencia y la imposición, pero no el debate ni la confrontación ideológica. La tercera idea es la necesidad de aceptar la diversidad pero sin que esta aceptación suponga "renunciar a las convicciones personales o atemperarlas".

En relación con la primera idea — rechazo de la abstención, de la indiferencia relativista - Buber afirma que podemos percibir al otro de tres maneras: como observador, como contemplador o conocerlo íntimamente. Sólo esta última manera permite conocer al otro como sujeto y no 
como objeto. El diálogo entre W necesita igualmente una actitud precisa entre los interlocutores. El diálogo debe "ser auténtico, de certeza a certeza, y de corazón abierto a corazón abierto (...). El diálogo no se limita al comercio entre los hombres; es (...) un comportamiento de hombres, el uno hacia el otro, un comportamiento que sus relaciones no hacen más que simplemente representar" (M. Buber, 1959, p. 112).

J. Hersch ha hablado de mímesis. La alternativa es, dice:

“¿voy a imponer al otro mi pensamiento, mi convicción mi manera de organizar la vida (...) o voy a intentar por medio de la imaginación a todos los niveles (...) de «mimar», con mi propio ser, el pensamiento, la convicción, lo «verdadero» y el «bien» del otro y su manera de organizar la vida, admitiendo en mi actitud primera limitaciones o errores que han podido provocar mutilaciones de mi posible condición humana, condición que es de mi deber, de sujeto libre y responsable, realizar?" (J. Hersch, 1995, p. 54).

Con respecto a la relación a la verdad, conviene recordar lo que hemos escrito al hilo de las reflexiones de G. Marcel sobre la tolerancia:

"la diversidad es conflictiva, o puede serlo, cuando la Weltanschauung plantea su acción a nivel del «tener» del «poseer» y no del «ser». Ahora bien plantearse la defensa de la verdad en términos de posesión es estrictamente contradictorio, es esto lo que nos repugna cuando alguien dice que está en la verdad, tenemos la impresión que «posee» la verdad y esto nos parece incompatible con la dignidad humana". (A. Fernandez, 2004, p. 251)

Por último, conviene insistir sobre la igualdad entre las diferentes W, aunque esta igualdad sea casi siempre relativa. Esta ha sido, según los especialistas, la principal dificultad en las historia porque todos los encuentros entre culturas se han desarrollado en condiciones de desigualdad. Siempre ha habido un invasor y un invadido. Maalouf ha puesto de manifiesto, de manera lúcida, el papel de la humillación de las otras culturas hacia el Occidente 
en la actual crisis internacional ${ }^{21}$. Es urgente restablecer un cierto equilibrio, este restablecimiento, sin caer en un victimismo, impone asumir con lucidez el pasado y las responsabilidades que esta asunción conlleva para la cultura occidental.

\section{BIBLIOGRAFÍA}

R. ARNALDEZ (1993), A la croisée des trois monothéismes. Une communauté de pensée au Moyen Age,Albin Michel, Paris.

M. Buber (1959), La vie en dialogue, Aubier Montaigne, Paris.

M. EliAde (1982) prefacio a Douglas ALLEN, Mircea Eliade et le phénomène religieux, Payot, Paris.

A Fernandez (2004) Diversidad cultural y universalidad de los derechos humanos. Materiales sobre los presupuestos del diálogo intercultural.in Anuario de Derechos humanos, Instituto de Derechos Humanos, Universidad Complutense, Madrid, volumen 5.

J. C. Gulllebaud (2005) La force de conviction, Seuil, Paris.

J. HERSCH (1995) Entre libérté et vérité, in UNESCO, Tolérance j’écris ton nom, Editions Saurat/UNESCO, Paris.

H. Hude (1991) Prolegomènes, Editions Universitaires, Paris.

J. Rof Carballo (1997) Violencia y ternura, col. Austral, Espasa, Madrid.

M. SCHeler (1960) El puesto del hombre en el cosmos, Losada, Buenos Aires.

A Wohlman (1988), Thomas d'Aquin et Maïmonide, un dialogue exemplaire, Cerf, Paris.

${ }^{21}$ A MaAlouf (2001) Les identités meurtrières, Livre de Poche, París. 